\title{
RESEARCH OF SELF-ESTEEM OF YOUTH USING IMPLICIT ASSOCIATION TESTS AND SELF-REPORTED PROCEDURES
}

\author{
Irina Plotka \\ Baltic International Academy, Latvia \\ Nina Blumenau \\ Baltic International Academy, Latvia \\ Elena Ozola \\ Daugavpils University, Latvia \\ Svetlana Pogildjakova \\ Baltic International Academy, Latvia \\ Jelena Drozdova \\ Baltic International Academy, Latvia
}

\begin{abstract}
Research aim is to investigate self-esteem of young people, using Single-Category Implicit Association Tests (SC-IAT) and self-reported procedures. Research questions: Are there differences between effects of implicit self-associations: performance, social, appearance and general? What factors can describe a set of measured implicit and explicit variables, characterizing self-esteem? Are the results of implicit and explicit measurements independent from each other? What are the features of the contribution of explicit global selfesteem, state self-esteem (performance, social, appearance) and implicit self-associations (performance, social, appearance) into the implicit general self-associations? Is there the compliance of measurement results of self-esteem obtained with SC-IAT and self-reported procedures? Method: Participants - 132, age 18-30 years $(M=25.4, S D=4.0)$. Implicit measures: Modified versions of SC-IAT: SC-IAT_1 (Performance self-associations, D $(P)$ ), SC-IAT_2 (Social self-associations, D(S)), SC-IAT_3 (Appearance self-associations, D $(A)$ ), SC-IAT_4 (General self-associations, D(SA)), developed on the basis of SC-IAT. Explicit measures: Rosenberg Self-Esteem Scale and State Self-Esteem Scale by Heatherton and Polivy. Results: Partial correspondence of measurements' results using IAT and self-reported procedures was found. It was found that the main contribution to the General selfassociations is made by the Social self-associations, Appearance self-associations and Rosenberg's Self-Esteem. The results of implicit and explicit measurements are independent from each other.
\end{abstract}

Keywords: attitude, appearance self-esteem, global self-esteem, SC-IAT, performance selfesteem, stateself-esteem, social self-esteem, self-associations. 
Irina Plotka, Nina Blumenau, Elena Ozola, Svetlana Pogildjakova, Jelena Drozdova. Research of Self-Esteem of Youth using Implicit Association Tests and Self-Reported Procedures

\section{Introduction}

After all various studies of self-esteem, a lot of issues yet remain obscure. Should self-esteem be understood primarily as a state or a trait, as affectively or cognitively based, as a global construct or as a domain-specific one? Do people have two distinct forms of self- esteem: one explicit and the other implicit? The concept of self-esteem is rather important for a human being as it is related to various aspects of life: society challenges (unemployment, violence, academic underachievement), subjective outcomes (life satisfaction, relationship satisfaction), as well as important objective outcomes (academic achievement, relationship stability and physical health) (Zeigler-Hill \& Jordan, 2010, 392). The study of such a psychological construct as self-esteem is necessary both to understand one's own behaviour, and to understand and predict the behaviour of others.

Understanding of the construct of self-esteem.

The term self-esteem is used in different ways by different researchers.

There are various approaches related to understanding of self-esteem, such as Global self-esteem, State self-esteemand Self-evaluations (Domain Specific self-esteem) (Brown \& Marshall, 2006).

Global self-esteem or trait self-esteem is relatively enduring across time and situations. It refers to a personality variable that represents the way people generally feel about themselves. A cognitive approach assumes that global selfesteem is a decision an individual makes about his/her worth as a person. Other approach emphasizes emotional processes and defines global self-esteem as a feeling of affection for oneself that is not derived from rational, judgmental processes (Brown \& Marshall, 2006, 2). However, it is defined that global selfesteem has been shown to be stable throughout adulthood, with a probable genetic component related to temperament and neuroticism (Neiss, Sedikides \& Stevenson, 2002).

According to Rosenberg (1965) (RSE), self-esteem is an evaluation of oneself. It is the evaluative aspect of self-knowledge that reflects how much people like themselves. Global self-esteem is typically defined as one's overall sense of worthiness as a person. The RSE can give better picture of the person's state in relation to other people. The results also include a little bit more about the relationship between one's self esteem and life outcomes (Zeigler-Hill \& Jordan, 2010, 392).

Self-esteem is also used to refer to self-evaluative emotion reactions to valenced events. Many researchers use the term state self-esteem to refer to the emotions we are calling feelings of self-worth, and trait self-esteem to refer to the way people generally feel about themselves (e.g., Heatherton \& Polivy, 1991). Other researchers disagree, arguing that momentary emotional reactions 
to positive and negative events do not provide an appropriate analogue for how people generally feel about themselves (Brown \& Marshall, 2006, 2).

According to subsequent views, however, self-esteem can be viewed as a "state," as well as a trait (Heatherton \& Polivy, 1991). Around a stable baseline there are fluctuations; although we might generally feel good about ourselves, there are times when we may experience self-doubt and even dislike. Fluctuations in state self-esteem are associated with increased sensitivity to and reliance on social evaluations, increased concern about how one views the self, and even anger and hostility (Kernis, 1993). In general, those with a fragile sense of self-esteem respond extremely favourably to positive feedback and extremely defensively to negative feedback.

Self-evaluation (Domain Specific Self-Esteem) is used to refer to the way people evaluate their various abilities and attributes. Brown and Marshall (2006, 2) prefer to call these beliefs self-evaluations or self-appraisals, as they refer to the way people evaluate or appraise their physical attributes, abilities, and personality characteristics. Not everyone makes this distinction, however. In fact, many scales that assess self-esteem include subscales that measure selfevaluations in multiple domains.

Self-esteem is an evaluative aspect of self-concept. Self-esteem is an attitude towards the self and is related to personal beliefs about skills, abilities, social relationships, and future outcomes. Although influenced by the contents of the self-concept, self-esteem is not the same thing (Heatherton \& Wyland, 2003, 220). Self-concept refers to the totality of cognitive beliefs that people have about themselves. By contrast, self-esteem is the emotional response that people experience as they contemplate and evaluate different things about themselves. There is common understanding of self-esteem according to APA Concise Dictionary of Psychology $(2009,454)$ : "Self-esteem - the degree to which the qualities and characteristics contained in one's self-concept are perceived to be positive. It reflects a person's physical self-image, view of his or her accomplishments and capabilities, and values and perceived success in living up to them, as well as the ways in which others view and respond to that person."

The decision to use a trait or state measure of self-esteem, therefore, depends on whether one is interested in predicting long-term outcomes or in the immediate effects associated with feelings about the self (Heatherton \& Wyland, 2003).

In addition to the existence of different definitions of the concept of selfesteem, various authors highlight such forms of self-evaluation asexplicit selfesteem and implicit self-esteem. Explicit self-esteem is defined as evaluation of oneself. It is the evaluative aspect of self-knowledge that reflects how much people like themselves. Explicit self-esteem is measured with explicit (direct) 
methods, when participants have introspective access to their self-esteem. Advantages of explicit measurements allow participants to rely on selfawareness that cannot be accessible to others. They are characterized by psychometric properties such as internal consistency, test-retest reliability, convergent validity and predictive validity (Zeigler-Hill \& Jordan, 2010, 393). Among disadvantage of explicit measurements there is the effect of social desirability of participants, provoking to answer to the items of self-report scales so as to avoid hurting the feelings of self-worth. Also, people may not have introspective access to all aspects of their self-esteem.

Implicit self-esteem is defined as "introspectively unidentified (or inaccurately identified) effect of the self-attitude on evaluation of self-associated and self-dissociated objects" (Greenwald \& Banaji, 1995, 11); "the strength of evaluative self-associations, which operate in a relatively automatic fashion, outside of conscious awareness" (Karpinski \& Steinberg, 2006, 103); "implicit attitude towards the self" (Dijksterhuis, 2004, 353). Implicit self-esteem are evaluations that are cognitively associated with the self and activated in response to self-relevant stimuli but that are not necessarily endorsed as valid reflections of how one feels about oneself, while explicit self-esteem is propositional, self-evaluative judgment that people endorse as valid (ZeiglerHill \& Jordan, 2010, 394). The advantage of implicit measurements is that for individuals it is often difficult to control their answers, even if they understand what is being measured. Implicit measurements can be connected to such aspects of self that the person does not know or does not want to report during direct measurements.

Implicit self-esteem is measured using methods such as the Implicit Association Test (IAT or Self-other IAT) (Greenwald, McGhee \& Schwartz, 1998), Single-Category IAT (SC-IAT or Self-SC-IAT) (Karpinski \& Steinman 2006), name-letter task, as well as other implicit methods. Measurements on the base of associations directly assess one's own associations, so it possible to obtain implicit self-esteem in a relatively pure form.

An important research issue of self-esteem construct with implicit and explicit methods is the independence of the results. To explain the dynamics of the interaction between implicit and explicit self-esteem constructs the following hypothesis are being proposed nowadays (Jordan, Logel, Spencer, Zanna \& Whitfield, 2012): the hypothesis of independence, hypothesis of equal relationships and hypothesis of hierarchy. Various details about the relationship between implicit and explicit self-esteem show a mixed picture. Explicit and implicit forms of self-esteem are independent constructs, since significant correlations between implicit and explicit self-esteem in some studies were found. In other studies significant correlations were found at least under certain experimental conditions, or on some samples. Two approaches to understanding 
and conceptualization of the construct of self-esteem can be defined. In the frameworks of the first approach self-esteem is considered as a multidimensional construct with relatively independent components. From this perspective, there are three major components of state self-esteem: performance self-esteem, socialself-esteem, and physical (appearance) self-esteem (Heatherton \& Polivy, 1991). Another approach understands the self-esteem as a single global construct.

So far there is no clear answer how components of self-esteem are associated with global self-esteem. Therefore, it remains the main focus of most theories of self-esteem.

Based on the assumption that self-esteem may be defined as a multidimensional construct with relatively independent components, some authors have developed SC-IAT procedures for each component of self-esteem construct. A. Karpinski (2004) recently criticized IAT measures of self-esteem, arguing that their measurements of self-associations are compromised by their contrasting self with a putatively extremely negative second category, the nonspecific other. Karpinski (2004) implied that validity of the self-esteem IAT depends on the valence of the concept of nonspecific other. The Single Category IAT (SC-IAT) is a modification of the IAT that measures the strength of evaluative associations with a single attitude object (Karpinski \& Steinman, 2006). It eliminates the need for the second contrast category. The self-SC-IAT scores are such that higher scores indicate greater positive than negative associations with the self.

For the adequate selection of assessment characteristics semantically related to one or another aspect of self-esteem the content of State Self-Esteem Scale (SSES) was used (Heatherton \& Polivy, 1991).

The aim of research is to investigate self-esteem of young people with using SC-IAT and self-reported procedures.

\section{Research questions:}

1. Are there differences between effects of implicit self-associations for performance self-associations, social self-associations, appearance self-associations and general self-associations?

2. What factors can describe a set of measured implicit and explicit variables, characterizing self-esteem?

3. Are the results of implicit measurements (self-associations) and explicit measurements (global self-esteem, state self-esteem and its component) independent from each other?

4. What are the features of the contribution of explicit global selfesteem, state self-esteem scales (appearance, performance and social) and implicit self-associations, performance self-associations and 
Irina Plotka, Nina Blumenau, Elena Ozola, Svetlana Pogildjakova, Jelena Drozdova. Research of Self-Esteem of Youth using Implicit Association Tests and Self-Reported Procedures

social self-associations into the general self-associations, measured with the SC-IAT?

5. Is there the compliance of measurement results of self-esteem obtained with SC-IAT and self-reported procedures?

\section{Method}

Participants -132 students, 17-male, 43-female, aged 18-30 years, $(M=25.4$, $\mathrm{SD}=4.0)$.

\section{Explicit methods}

Rosenberg Self-Esteem Scale (RSE) (Rosenberg, 1965, 1979). The RSE is the most widely used measure of global self-esteem. The scale ranges from 0 to 30 points. Results from 24 to 30 points show high self-esteem; results from 13 and 24 are within the normal range; scores below 13 points indicate low selfesteem and an opportunity to work at self-improvement and learn to believe in himself/herself.

State Self-Esteem Scale (SSES) (Heatherton \& Polivy, 1991) was translated into Russian and Latvian (direct and reverse translation, two independent bilingual translators). Reliability of the Russian version of the scale has been checked on a sample of 155 students.

The performance factor of the SSES measures the extent to which subjects feel their performance is worthy; it would probably be most sensitive to laboratory manipulations that use bogus performance feedback or unsolvable tasks (Heatherton \& Polivy, 1991, 907). It refers to a sense of general competence, which includes intellectual ability, academic performance, ability to self-regulation, confidence, efficiency, freedom of action. People with high levels of this component of self-esteem feel confident in their intelligence and abilities.

The social factor of the SSES was the most strongly related to public selfconsciousness and social anxiety, which suggests that it measures the extent to which individuals feel self-conscious, foolish, or embarrassed about their public image. This factor should be most sensitive to situations in which selfpresentational concerns are threatened (Heatherton \& Polivy, 1991, 907). It indicates how, according to the person, others perceive him/her. It should be considered that it better reflects the perception than reality. If a person is sure that others, especially significant others appreciate and respect him/her the sense of social self-esteem is high. This will happen even if the others do not really feel respect for him/her. Persons with low self-esteem often experience social sense of social anxiety and embarrassment, shyness in public. Such people are very attentive to their image and are worried about how they are seen by the others. 
The appearance factor of the SSES would probably be most sensitive to manipulations that make physical appearance salient (Heatherton \& Polivy, 1991, 907). It refers to how the person sees his/her physical parameters, including athletic skills, physical attractiveness, body image, as well as physical disabilities and a sense of race and ethnicity (Heatherton \& Polivy, 1991, p. 907).

\section{Implicit methods:}

Modified versions of Single-Category Implicit Association Tests (SC-IAT): IAT_1 (Performance self-association), SC-IAT_2 (Social self-association), SCIAT_3 (Appearance self-association), developed on the basis of SC-IAT (Karpinski \& Steinman, 2006). For each procedure the appropriate categories and attributes were identified. For correct selection of categories for measuring the self-esteem, the authors relied on the theoretical approaches of SSES (Heatherton \& Polivy, 1991).

The categories of all SC-IAT were: I, me, my, myself. The attributes - the words with a strong affective meaning (positive or negative) were used. Positive and negative target words:

Performance self-associations - success, competence, knowledge, abilities, confidence, failure, incompetence, ignorance, futility, doubt;

Social self-associations - recognition, respect, openness, popularity, confidence, disregard, contempt, shyness, failure, anxiety;

Appearance self-associations - attractiveness, beauty, charm, grace, unattractiveness, ugliness, disgust, clumsiness.

Also SC-IAT_4 (self-associations) was designed with categories: I, me, my, myself, and positive and negative target words: love, joy, peace, happiness, good; anger, disgust, contempt, evil, hatred from modification of Schlosberg Scale (Woodworth, Schlosberg, 1955; Schlosberg, 1952). SC-IAT - measure of self-associations was accepted as a basic (Karpinski \& Steinman, 2006, 19, 22).

Apparatus: Certified licensed software E-Prime 2®.

Procedure of the research. All the participants took part in the research voluntarily. The research was conducted individually. Participants completed the tasks in the same order: SC-IAT measure of Self-Esteem and explicit measures of Self-Esteem. At the conclusion of the session the participants were thanked and completely debriefed.

SC-IAT measure of Self-Esteem. The evaluative dimension was labelled "good" and "bad", and the object dimension was labelled "self". The SC-IAT consisted of two stages, which participants completed in the same order. Each stage consisted of 24 practice trials immediately followed by 72 test trials (three blocks of 24 trials each). Participants first completed the self - positive blocks, followed by the self - negative blocks. In the first stage ("I am good"), category words and good target words were categorized on the "Q" key, and bad target 
words were categorized on the "P" key. In the second stage ("I am bad"), good words were categorized on the "Q" key, and category words and bad words were categorized on the "P" key. Within each category, words were selected randomly without replacement. Each stage was preceded by a set of instructions concerning the dimensions of the categorization task and the appropriate key responses. Each target word appeared centred on the screen. All target and category words were presented in lowercase letters. Category reminder labels were appropriately positioned on the bottom fourth of the screen. The target word remained on the screen until the participants responded or for $1500 \mathrm{~ms}$. If participants failed to respond within $1500 \mathrm{~ms}$, a reminder to "Please respond more quickly!" appeared for $500 \mathrm{~ms}$. Before the start of the experiment, on a computer monitor a participant was given general instructions and specific instructions before each of the blocks (tasks). Performance of the four versions of the implicit method took an average of 30 to 40 minutes. To ensure the internal validity of the experiment the main parameters were unchanged (the time of stimulus presentation, the intervals between stimuli, number of stimuli the words, the font, chromatic background settings). The task of the participants was the differentiation of presented verbal stimuli. Stimulus word displayed on the screen without auditory accompaniment and remained on the screen until the response (pressing a key) of the participant. The reaction time (RT) for each trail was recorded as the time interval between the onset of stimulus presentation and pressing the correct key. The order of stimulus presentation was given at random.

Explicit measures of self-esteem. Participants next completed two explicit measures of self-esteem: Rosenberg RSE and SSES. For the Rosenberg scale, participants responded to each item on a 7-point scale ranging from 1 (disagree strongly) to 7 (agree strongly). The 10 items were averaged to compute a measure of self-esteem $(\alpha=.837)$. Cronbah- $\alpha$ for SSES: Performance Selfesteem $(\alpha=.725)$, Social Self-esteem $(\alpha=.807)$, Appearance Self-esteem $(\alpha=.721)$.

\section{Results}

\section{Explicit measured variables}

Variables "Rosenberg Self-Esteem Scale" - RSE and "State Self-Esteem Scale" - SSES (Heatherton \& Polivy, 1991): total - SSEST, performance SSESP, social - SSESS, appearance - SSESA were measured with explicit methods.

\section{Implicit measured variables}

As a result of SC-IAT the D-scores for implicitly measured variables "Performance self-associations" - D $(P)$; "Social self-associations" - D(S); 
"Appearance self-associations" - D(A); "General Self-associations" - D(SA) were calculated.

\section{Statistical methods}

With research of descriptive statistics, extreme values of variables and compliance of data distribution with normal distribution it was found that all variables can be researched by methods of parametric statistics, using t-tests for means, Pearson's correlation coefficients and Multiple Regression Analysis, Repeated Measures ANOVA and Factor Analysis.

To answer the first research question, the research of implicit self-associations, expressed in D-scores was conducted. To calculate the effect of implicit self-associations we used D-statistics (Rudman, 2011). The D-statistic is an effect size, based on each person's variance in response latencies. If $|\mathrm{D}| \leq 0.15$ - no effect, if $0.15<|\mathrm{D}| \leq 0.35$ - small effect size, if $0.35<|\mathrm{D}|<0.60$ - medium effect size, if $|\mathrm{D}| \geq 0.60$ - large effect size. The self-SCIAT scores were such that higher scores indicated greater positive than negative associations with the self.

Both positive and negative effects for implicit self-associations were obtained (Table 1).

Table 1 Percentages for implicit self-associations

\begin{tabular}{|l|c|c|c|c|}
\hline & $\mathbf{D}(\mathbf{A})$ & $\mathbf{D}(\mathbf{P})$ & $\mathbf{D}(\mathbf{S})$ & $\mathbf{D}(\mathbf{S A})$ \\
\hline Negative & 16.7 & 18.9 & 28.0 & 13.6 \\
No preference & 36.4 & 29.5 & 29.5 & 24.2 \\
Positive & 47.0 & 51.5 & 42.4 & 62.1 \\
\hline
\end{tabular}

With the help of Fisher's Angle Transformations Test it was found that the number of positive self-associations exceeds the number of negative selfassociations (for $\mathrm{D}(\mathrm{A}): \phi^{*}=5.43, \mathrm{p}<.001$; for $\mathrm{D}(\mathrm{P}): \phi^{*}=5.70, \mathrm{p}<.001$; for $\mathrm{D}(\mathrm{S})$ ): $\phi^{*}=2.43, \mathrm{p}<.01$; for $\left.\mathrm{D}(\mathrm{SA}): \phi^{*}=8.61, \mathrm{p}<.001\right)$.

Differences between mean values and 0.15 - the lower border of the zone of effect's beginning (One-Sample t-test) for variables $\mathrm{D}(\mathrm{S})$ and $\mathrm{D}(\mathrm{SA})$ are statistically significant: $\mathrm{D}(\mathrm{S}): \mathrm{t}(131)=-2.66 ; \mathrm{p}<.01, \mathrm{D}(\mathrm{SA}): \mathrm{t}(131)=2.93 ; \mathrm{p}<.01$. Differences between mean values and zero for all variables are statistically significant: $\mathrm{D}(\mathrm{A}): \mathrm{t}(131)=6.27 ; \mathrm{p}<.001, \mathrm{D}(\mathrm{P}): \mathrm{t}(131)=4.88 ; \mathrm{p}<.001), \mathrm{D}(\mathrm{S})$ : $\mathrm{t}(131)=2.26 ; \mathrm{p}<.05, \mathrm{D}(\mathrm{SA}): \mathrm{t}(131)=8.06 ; \mathrm{p}<.001$. Variables' $\mathrm{D}(\mathrm{S})$ and $\mathrm{D}(\mathrm{SA})$ means are above the lower border of the zone of effect's beginning (0.15).

By using Repeated Measures ANOVA the influence of the factor selfassociations on D-scores was established: test between subject effects, $\mathrm{F}(1,131)$ $=65.97, \mathrm{p}<.001, \eta^{2}=.335$. For comparison of mean values (Fig. 1) the Paired Samples t-test was used. It was found that $\mathrm{D}(\mathrm{A})$ was significantly higher than 
$\mathrm{D}(\mathrm{S})(\mathrm{t}(131)=2.90, \mathrm{p}<.01), \mathrm{D}(\mathrm{SA})$ is higher than $\mathrm{D}(\mathrm{P})(\mathrm{t}(131)=-2.76, \mathrm{p}<.01)$, $\mathrm{D}(\mathrm{SA})$ is higher than $\mathrm{D}(\mathrm{S})(\mathrm{t}(131)=-4.80, \mathrm{p}<.001)$.

To answer the second research question, what factors can determine the set of measured implicit and explicit variables that characterize self-esteem, the authors held Factor Analysis with two factors (Kaiser criterion), method Maximum likelihood, rotation's method Varimax with Kaiser Normalization, Kaiser-Meyer-Olkin (KMO) measure of sampling adequacy equals to 0.64 (satisfactory adequacy of the sample), Bartlett's test of Sphericity $\chi 2(28)=$ $143.30, \mathrm{p}<.001$ (data are suitable for factor analysis), cumulative percent of total variance explained $31.4 \%$, goodness of fit test $\chi^{2}(13)=19.23, \mathrm{p}=.116$, ns (factor model adequately describes the relationships among the variables). As a result, it was found that Factor 1 only describes explicit variables (RSE, SSESA, SSESP, SSESS) and the second factor describes only implicit variables (D (A), D (P), D (S), D (SA)) (Fig. 2). These factors can be called the "Explicit selfesteem factor" and "Implicit self-associations factor".

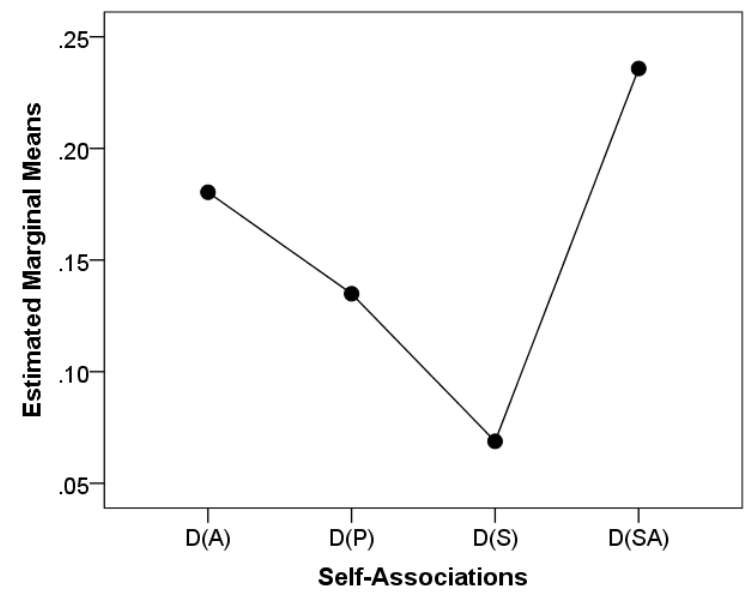

Fig. 1 Estimated Marginal Means.

$\mathrm{M}(\mathrm{A})=.18, \mathrm{SD}(\mathrm{A})=.33 ; \mathrm{M}(\mathrm{P})=.13$,

$\mathrm{SD}(\mathrm{P})=.32 ; \mathrm{M}(\mathrm{S})=.07, \mathrm{SD}(\mathrm{S})=.35$;

$\mathrm{M}(\mathrm{SA})=.26, \mathrm{SD}(\mathrm{SA})=.34$

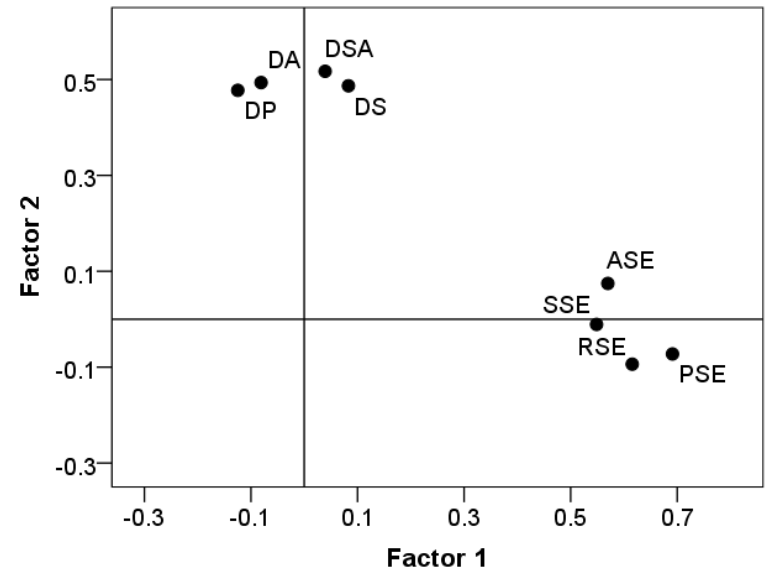

Fig. 2 Factor Plot in Rotated Factor Space. Notations: $\mathrm{DA}=\mathrm{D}(\mathrm{A}), \mathrm{DP}=\mathrm{D}(\mathrm{P}), \mathrm{DS}=\mathrm{D}(\mathrm{S})$, DSA=D(SA), SSE=SSESS, ASE=SSESA, PSE=SSESP.

To answer the third research question Pearson correlation coefficients were calculated. Correlation between explicit measurements of self-esteem is positive, statistically significant. Correlation between implicit measurements of self-esteem is positive, statistically significant (Table 2). At the same time, all the coefficients of correlation between explicit and implicit measurements are statistically insignificant. The result of factor analysis is not unexpected. 
Proceedings of the International Scientific Conference. Volume I, May $27^{\text {th }}-28^{\text {th }}$, 2016. 483-497

Table 2 Statistically significant Pearson correlation coefficients

\begin{tabular}{|c|c|c|c|}
\hline Variables & Pearson Correlation & Variables & Pearson Correlation \\
\hline RSE-SSEST & $\mathrm{r}(132)=.489, \mathrm{p}<.001$ & $\mathrm{D}(\mathrm{A})-\mathrm{D}(\mathrm{P})$ & $\mathrm{r}(132)=.308, \mathrm{p}<0.001$ \\
\hline RSE-SSESP & $\mathrm{r}(132)=.405, \mathrm{p}<.001$ & $\mathrm{D}(\mathrm{A})-\mathrm{D}(\mathrm{S})$ & $\begin{array}{l}\mathrm{r}(132)=.159, \mathrm{p}=.068, \mathrm{~ns} \\
\mathrm{r}(132)=.240,\end{array}$ \\
\hline RSE-SSESS & $\mathrm{r}(132)=.348, \mathrm{p}<.001$ & $\mathrm{D}(\mathrm{A})-\mathrm{D}(\mathrm{SA})$ & $\begin{array}{l}\mathrm{p}=.005<.01 \\
\mathrm{r}(132)=.242\end{array}$ \\
\hline RSE-SSESA & $\mathrm{r}(132)=.371, \mathrm{p}<.001$ & $\mathrm{D}(\mathrm{P})-\mathrm{D}(\mathrm{S})$ & $\begin{array}{l}\mathrm{p}=.005<.01 \\
\mathrm{r}(132)=.177\end{array}$ \\
\hline SSEST-SSESP & $\mathrm{r}(132)=.754, \mathrm{p}<.001$ & $\mathrm{D}(\mathrm{P})-\mathrm{D}(\mathrm{SA})$ & $\mathrm{p}=.043<.05$ \\
\hline SSEST-SSESS & $\mathrm{r}(132)=.802, \mathrm{p}<.001$ & $\mathrm{D}(\mathrm{S})-\mathrm{D}(\mathrm{SA})$ & $\mathrm{r}(132)=.324, \mathrm{p}<.001$ \\
\hline SSEST-SSESA & $\mathrm{r}(132)=.666, \mathrm{p}<.001$ & & \\
\hline SSESP-SSESA & $\mathrm{r}(132)=.401, \mathrm{p}<0.001$ & & \\
\hline SSESP-SSESS & $\mathrm{r}(132)=.402, \mathrm{p}<0.001$ & & \\
\hline SSESA-SSESS & $\mathrm{r}(132)=.268, \mathrm{p}=.002<.01$ & & \\
\hline
\end{tabular}

To answer the fourth research question the Regression Analysis was applied.

To research the contribution of independent variables to the variable "D(SA)" the multiple regression analysis was used. Dependent Variable: D(SA). Independent Variables: $\mathrm{D}(\mathrm{A}), \mathrm{D}(\mathrm{P}), \mathrm{D}(\mathrm{S})$, SSESA, SSESP, SSESS, SSEST, RSE.

Method "Backward". Method's: criteria: probability-of- $F$-to-enter $\leq 0.050$, probability-of- $F$-to-remove $\geq 0.101$. The equation for estimations:

$\mathrm{D}(\mathrm{SA})($ estimate $)=0.167+0.298 * D(\mathrm{~S})+0.190 * \mathrm{D}(\mathrm{A})-0.010 * \mathrm{RSE}+0.010 * \mathrm{SSESS}$.

The impact of each independent variable is defined by "Beta-coefficients" $(\beta)$. The Beta coefficients are the coefficients in standardized regression equation.

The greatest impact on " $\mathrm{D}(\mathrm{SA})$ " is made by the variable $\mathrm{D}(\mathrm{S})\left(\beta_{1}=.310\right.$, $p<.001)$ then, by $\mathrm{D}(\mathrm{A})\left(\beta_{2}=.187, p<.05\right)$, then by $\operatorname{RSE}\left(\beta_{3}=-.179, p<.05\right)$ and then by SSESS $\left(\beta_{4}=.142, p=0.101\right) . R$-Square=.176 shows, that $17.6 \%$ of variability of the dependent variable " $\mathrm{D}(\mathrm{SA})$ " is due to the influence of the independent variables $\mathrm{D}(\mathrm{S}), \mathrm{D}(\mathrm{A}), \mathrm{RSE}$ and SSESS. Adjusted $R$-square $=.150$. Standard error of estimate is 0.310 . The result of ANOVA is: $F(4,127)=6.763$; $p<.001$.

Method "Enter". The equation for estimations:

$\mathrm{D}(\mathrm{SA})($ estimate $)=-0.025+0.293 * D(\mathrm{~S})+0.191 * \mathrm{D}(\mathrm{A})-0.011 * \mathrm{RSE}+$ $+0.010 *$ SSESP $+0.008 *$ SSESS $+0.001 *$ SSESA. 
Irina Plotka, Nina Blumenau, Elena Ozola, Svetlana Pogildjakova, Jelena Drozdova. Research of Self-Esteem of Youth using Implicit Association Tests and Self-Reported Procedures

The greatest impact on " $\mathrm{D}(\mathrm{SA})$ " is made by the variable $\mathrm{D}(\mathrm{S})\left(\beta_{1}=.305\right.$, $p<.001)$, then by RSE $\left(\beta_{2}=-.207, p=.031<.05\right)$, then, by $\mathrm{D}(\mathrm{A})\left(\beta_{3}=.188\right.$, $p=.035<.05)$, then by SSESS $\left(\beta_{4}=0.112\right.$, ns $)$, then by SSESP $\left(\beta_{5}=0.096\right.$, ns $)$, then by $\mathrm{D}(\mathrm{P})\left(\beta_{6}=.031, \mathrm{~ns}\right)$ and then by SSESA $\left(\beta_{7}=.012, \mathrm{~ns}\right) . R$-Square $=.184$ shows, that $18.4 \%$ of variability of the dependent variable " $\mathrm{D}(\mathrm{SA})$ " is due to the influence of the independent variables $\mathrm{D}(\mathrm{S}), \mathrm{D}(\mathrm{A}), \mathrm{D}(\mathrm{P})$, RSE, SSESA, SSESP and SSESS. Adjusted $R$-square=.138. Standard error of estimate 0.312. The result of ANOVA is: $F(7,124)=3.995 ; p<.001$.

To answer the fifth research question the compliance of results of implicit and explicit measurements was verified.

The research of congruence of measurement results, obtained with experimental procedures of the SC-IAT (variables $\mathrm{D}(\mathrm{A}), \mathrm{D}(\mathrm{P}), \mathrm{D}(\mathrm{S})$ ) and selfreported procedures (variables SSESA, SSESP, SSESS accordingly) was performed using Pearson's correlation coefficients, as well as by calculating the percent of matching results. The relationship is not monotonic. Therefore, its research was conducted at areas with varying severity of explicit and implicit effects. The results of measurements $X$, obtained by the explicit methods, were divided by quartiles $\mathrm{Q}_{1}$ and $\mathrm{Q}_{3}$ into levels: $\mathrm{X} \leq \mathrm{Q}_{1}$ - low, $\mathrm{Q}_{1}<\mathrm{X}<\mathrm{Q}_{3}$ - normal, $X \geq Q_{3}$ - high. The results of the measurements D-scores, obtained with the SCIAT were divided into groups according to (Rudman, 2011): $|D| \leq 0.15$ - no effect, $\mathrm{D}<-0.15$ - negative effect, $\mathrm{D}>0.15$ - positive effect.

Pearson's correlation coefficients.

The results showed compliance of implicit and explicit measurements of researched constructs evaluated by the correlation coefficients, the values of which fall within the valid range from .12 to .72 (Rudman, 2011). In the entire range of variables variation the correlation coefficients are statistically insignificant and do not fall into the interval (.12; .72). The Pearson's correlation coefficients from this interval are shown in Table 3.

Table 3 Pearson correlation coefficients in the interval $(.12 ; .72)$ for different levels of variables

\begin{tabular}{|c|c|c|c|}
\hline Variables & \multicolumn{2}{|c|}{ Levels } & Pearson Correlation \\
\hline D(A)-SSESA & D $(A)$ & negative effect & $\mathrm{r}(22)=.326, \mathrm{p}=.138$ \\
D(A)-SSESA & $\mathrm{D}(\mathrm{A})$ & positive effect & $\mathrm{r}(62)=.111, \mathrm{p}=.391$ \\
D(P)-SSESP & $\mathrm{D}(\mathrm{P})$ & positive effect & $\mathrm{r}(68)=.162, \mathrm{p}=.187$ \\
D(S)-SSESS & SSESS & low & $\mathrm{r}(37)=.196, \mathrm{p}=.244$ \\
$\mathrm{D}(\mathrm{S})-$ SSESS & SSESS & high & $\mathrm{r}(40)=.278, \mathrm{p}=.083$ \\
\hline
\end{tabular}

Calculation of percent.

To calculate percent match frequency analysis was used. Match will be the following results: (1) implicit variable „low” or „no effect” - explicit variable 
„low”. (2) For implicit variable: „positive” - explicit variable „high”. Obtained percentage of matches - SSESA and D(A) - $33.3 \%$; D(P) and SSESP - 26.5\%; $\mathrm{D}(\mathrm{S})$ and SSESS $-26.5 \%$. Total $-28.8 \%$.

\section{Conclusions and Discussion}

As a result of the research its aim was achieved and main results were presented.

Theoretical understanding of the concept of self-esteem led to the conclusion that the explicit self-esteem refers to feelings of self-worth or the global evaluation of the self. Approaches related to the understanding of selfesteem ascertain the existence of such «faces» as global self-esteem, state selfesteem and self-evaluation. According to subsequent views, however, selfesteem can be viewed as a state, as well as a trait (Heatherton \& Polivy, 1991). Researchers' address to the concept of implicit self-esteem is due to the fact that implicit measurements can provide information about those aspects of selfesteem, which people either do not know or do not want to report during explicit measurements.

Implicit self-esteem is a valenced association that a person has towards himself/herself. Researchers differ in how they characterize this association. Some consensus has emerged regarding its nature and properties (Burmester, Blanton \& Swann, 2011, p. 365). Valence of the association can be determined on the base of various markers (Rudman, 2011). In this work four procedures of SC-IAT have been developed. For the adequate selection of evaluation attributes in the first three experimental SC-IAT procedures the scales of the State SelfEsteem Scale (SSES) were chosen (Heatherton \& Polivy, 1991): Performance self-esteem, Appearance self-esteem and Social self-esteem. For the fourth procedure of SC-IAT the words from the Schlosberg Scale were used as attributes (Schlosberg, 1952). With four designed SC-IAT procedures the values (D-scores) of the following variables were measured: performance selfassociations, appearance self-associations, social self-associations and general self-associations. The term "global self-associations" was introduced by the authors to describe self-associations measured with the SC-IAT with attributes words of the SchlosbergScale. It is possible that the poles of the fundamental concepts of good and evil may be called the markers for such associations.

With the help of SC-IAT both positive and negative implicit selfassociations were obtained: performance, social, appearance and general. The number of positive self-associations exceeds the number of negative selfassociations. The means of self-associations are positive. Social self-associations are less expressed than appearance and general self-associations. General selfassociations are more expressed than performance self-associations. 
The set of measured explicit and implicit variables (global self-esteem, state performance self-esteem, state appearance self-esteem, state social selfesteem, performance self-associations, appearance self-associations, social selfassociations and general self-associations) is described with two factors: Explicit self-esteem factor which includes only explicit variables and Implicit selfassociations factor which includes only implicit variables.

All explicitly measured self-esteems are positively associated with each other. All implicitly measured self-associations are also positively associated with each other. Explicitly measured variables are not associated with implicitly measured variables (in the whole range of variation). The result of factor analysis is not unexpected.

The main contribution to general self-associations with the sign „plus” is made by social self-esteem and appearance self-esteem, and with the sign „minus”-by global self-esteem.

The research of congruence of measurement results, obtained with experimental procedures of the SC-IAT (variables $\mathrm{D}(\mathrm{A}), \mathrm{D}(\mathrm{P}), \mathrm{D}(\mathrm{S})$ ) and selfreported procedures (variables SSESA, SSESP, SSESS accordingly) was performed using Pearson's correlation coefficients, as well as by calculating the percent of matching results. The relationship is not monotonic. In the entire range of variables variation the correlation coefficients are statistically insignificant and do not fall into the interval $(0.12 ; 0.72)$ (Rudman, 2011). There are intervals of variables variation, on which Pearson correlation coefficients are quite high. The total percentage of matches of the results is $28.8 \%$.

Various data about the relationship between implicit and explicit selfesteem show a mixed picture. Explicit and implicit forms of self-esteem are independent constructs, since significant correlations between implicit and explicit self-esteem in some researches were not found. Some other studies found significant correlation, at least under certain experimental conditions, or on some samples. Implicit and explicit self-esteem may be related in a predictable manner and so that they can reflect the two sides of the dual process (Dijksterhuis \& Bongers, 2009, p. 233).

A limitation of this research is the absence of some other variables, by means of which it would be possible to study the validity of implicit measurements, as well as more fully describe the contributions of all variables in measured implicit associations. Another limitation to the research was that the research was conducted only on a sample of young people aged 18-30 years. Prospects for further research can be to attract participants of different age groups. 


\section{References}

APA Concise Dictionary of Psychology. (2009). Washington, DC: American Psychological Association.

Brown, J. D., \& Marshall, M. A. (2006). The three faces of self-esteem. In M. Kernis (Ed.), Self-esteem: Issues and answers (pp. 4-9). New York: Psychology Press.

Buhrmester, M. D., Blanton, H., \& Swann, W. B. J. (2011). Implicit self-esteem: Nature, measurement, and a new way forward. Journal of Personality and Social Psychology, 100 (2), 365-385.

Dijksterhuis, L. W. A., \& Bongers, K. C. A. (2009). Digging for the real attitude. In R. E. Petty, R. H. Fazio, \& P., Brinol (Eds.), Attitudes. Insights from the New Implicit Measures (pp. 229-250). New York: Psychology Press.

Coopersmith, S. (1967). The antecedents of self-esteem. San Francisco: Freeman.

Jordan, C. H., Logel, C., Spencer, S. J., \& Zanna, M. P. (2012). Discrepancies between implicit and explicit attitudes, prejudices, and self-esteem: A model of simultaneous accessibility. In B. Gawronski \& F. Strack (Eds.), Cognitive Consistency: A Unifying Concept in Social Psychology (pp. 202-222). New York: Guilford Press.

Heatherton, T. F., \& Wyland, C. L. (2003). Assessing self-esteem. In Lopez. J. Shane \& C. R. Snyder (Eds), Positive psychological assessment: A handbook of models and measures (pp. 219-233). Washington, DC, US: American Psychological Association.

Heatherton, T. F., \& Polivy, J. (1991). Development and validation of a scale for measuring state self-esteem. Journal of Personality and Social Psychology, 60, 895-910.

Karpinski, A. (2004). Measuring self-esteem using the Implicit Association Test: The role of the other. Personality and Social Psychology Bulletin, 30, 22-34.

Karpinski, A., \& Steinman, R. B. (2006). The Single Category Implicit Association Test as a measure of implicit social cognition. Journal of Personality and Social Psychology, 91 (1), 16-32.

Kernis, M. H. (1993) The role of staility and level of self-esteem in psychological functioning. In R. F. Baumeister (Ed.), Self-esteem: The puzzle of low self-regard (pp. 167-182). New York Plenum Press.

Neiss, M. B., Sedikides, C., \& Stevenson, J. (2002). Self-esteem: A behavioural genetics perspective. European Journalof Personality, 16, 1-17.

Rieger, S., Göllner, R., Trautwein, U., \& Roberts, B. W. (2016). Low Self-Esteem Prospectively Predicts Depression in the Transition to Young Adulthood: A Replication of Orth, Robins, and Roberts (2008). Journal of Personality and Social Psychology 110 (1), e16 - e22. http://dx.doi.org/10.1037/pspp0000037

Rosenberg, M. (1965). Society and the adolescent self-image. Princeton, NJ: Princeton University Press.

Rosenberg, M. (1979). Conceiving the self. New York: Basic Books

Rudman, L. A. (2011). Implicit measures for social and personality psychology. Rutgers University, USA: SAGE Publications.

Schlosberg, H. (1952). The description of facial expressions in terms of two dimensions. Journal of Experimental Psychology, 44, 229-237.

Woodworth, R. S., \& Schlosberg, H. (1955). Experimental psychology. London: Methuen.

Zeigler-Hill, V., \& Jordan, C. H. (2010). Two faces of self-esteem: Implicit and explicit forms of self-esteem. In B. Gawronski \& B. K. Payne (Eds.), Handbook of Implicit Social Cognition Measurement, Theory, and Applications (pp. 392-407). New York, London: The Guilford Press. 